\title{
Efeitos de dietas contendo Leucaena leucocephala e Saccharomyces cerevisiae sobre a fermentação ruminal e a emissão de gás metano em bovinos
}

\author{
Rosana Aparecida Possenti ${ }^{1}$, Raul Franzolin ${ }^{2}$, Eliana Aparecida Schammas ${ }^{3}$, João José \\ Assumpção de Abreu Demarchi ${ }^{3}$, Rosa Toyoko Shiraishi Frighetto ${ }^{4}$, Magda Aparecida de Lima ${ }^{4}$ \\ 1 Instituto de Zootecnia, Nova Odessa, SP. \\ 2 FZEA-USP, Pirassununga, SP. \\ ${ }^{3}$ APTA, Andradina, SP. \\ ${ }^{4}$ EMBRAPA Meio Ambiente Jaguariúna, SP.
}

RESUMO - Este trabalho foi realizado com o objetivo de avaliar os efeitos do uso de leucena e levedura em dietas para bovinos sobre o metabolismo ruminal, incluindo o $\mathrm{pH}$ e as produções de ácido graxos voláteis (AGV), amônia e gás metano. Quatro bovinos machos com $800 \mathrm{~kg}$ e fistulados no rúmen foram mantidos em quadrado latino $4 \times 4$, em arranjo fatorial $2 \times 2$, composto de dois níveis de leucena (20 e 50\% MS) e feno de capim coast-cross na presença ou ausência de levedura. Não houve influência das dietas nos valores médios de pH (média 6,82) e nas concentrações de amônia no rúmen, que variaram de 18 a $21 \mathrm{mg} / 100 \mathrm{~mL}$. Houve interação entre níveis de leucena e levedura na concentração total de AGV. As dietas não diferiram quanto à concentração de ácido acético, mas os animais alimentados com a dieta com 50\% de leucena e contendo levedura apresentaram maiores concentrações médias de ácido propiônico (média 19,14 mM). A emissão de metano reduziu em12,3\% em relação à mesma dieta sem levedura e em 17,2\% quando os animais foram alimentados com $20 \%$ de leucena com levedura. Verificou-se efeito associativo de leucena, quando fornecida em alto nível na dieta (50\% MS), e levedura na redução da emissão de metano e na melhoria no padrão de fermentação no rúmen, o que pode reduzir as perdas de energia e melhorar eficiência energética do animal.

Palavras-chave: ácidos graxos voláteis, gases ruminais, levedura, metabolismo ruminal

\section{Effects of leucaena and yeast on rumen fermentation and methane emissions in cattle}

\begin{abstract}
This research was to evaluate the effect of Leucaena (Leucaena leucocephala) and yeast (Saccharomyces cerevisiae) in diets for bovines on ruminal metabolism, including $\mathrm{pH}$, volatile fatty acids, and ammonia and methane production. Four crossbred male cattle ( $800 \mathrm{~kg} \mathrm{LW})$ rumen cannulated were distributed to a $4 \times 4$ Latin Square design, in $2 \times 2$ factorial arrangement, composed by two levels of Leucaena (20\% and 50\% DM) and coast-cross grass hay, with or without yeast. No differences were observed in rumen $\mathrm{pH}$ (mean 6.82) and ammonia concentrations that varied from 18.71 to $21.28 \mathrm{mg} / 100 \mathrm{~mL}$ of ruminal fluid. There was interaction between Leucaena levels and yeast in the total concentrations of VFA. No differences were observed in the concentrations of acetic acid, but the animals fed 50\% of Leucaena with yeast showed higher propionic acid concentration (19.14 mM). Methane emissions were reduced by $12.3 \%$ in relation to the same diet without yeast and in $17.2 \%$ when the animals were fed $20 \%$ of Leucaena with yeast. There was a noticeable associative effect of Leucaena when fed in high level (50\% DM) and yeast in the reduction of methane emission and better rumen fermentation with possible reduction of energy loss and better energy efficiency for the animals.
\end{abstract}

Key Words: ruminal gases, ruminal metabolism, volatile fatty acids, yeast

\section{Introdução}

A leucena (Leucaena leucocephala) é uma leguminosa arbórea de ampla versatilidade para uso em sistemas de produção animal como planta forrageira, tendo em vista sua excelente composição química e suas características agronômicas, bem como sua alta aceita- bilidade pelos animais (Lourenço \& Carriel, 1998; Valarini \& Possenti, 2004).

A implementação de práticas de manejo em pastos visando melhorar a produtividade animal, como a redução da emissão de metano, é de grande relevância para os sistemas de produção animal e preservação do meio ambiente. O uso de leguminosas na dieta visando redu- 
ção da produção de metano no rúmen tem sido pesquisado com estudos in vivo e in vitro em ruminantes consumindo baixos ou moderados teores de taninos (Puchala et al. 2005). Leveduras também são relacionadas à redução da produção de metano no rúmen por promover aumento da competição entre bactérias acetonogênicas e metanogênicas.

Aditivos em dietas para ruminantes, como leveduras, probióticos, tamponantes e outros, têm sido usados visando melhorar a relação simbiótica entre os microrganismos presentes no rúmen e seu hospedeiro, melhorando os processos fermentativos no rúmen em animais que recebem dietas ricas em amidos (Franzolin et al., 2004). São poucos e conflitantes os trabalhos que indicam o uso de leveduras para animais mantidos com dietas exclusivamente volumosas. Segundo Roa et al. (1997), as leveduras podem aumentar a digestibilidade da proteína bruta e da fibra em detergente neutro em dietas à base de feno de alfafa como fonte de fibra. Entretanto, Garcia et al. (2000) não observaram efeitos no pH e na fermentação ruminal em dietas contendo forragem de alta qualidade (50\% de alfafa e concentrado).

Objetivou-se com este trabalho avaliar os efeitos do fornecimento de Leucaena leucocephala associada ao feno de capim Cynodon dactylon cv. coast-cross na dieta sobre a ingestão de matéria seca, o pH ruminal e as produções de ácidos graxos voláteis, amônia e gás metano no rúmen.

\section{Material e Métodos}

O experimento foi conduzido no Instituto de Zootecnia de Nova Odessa, São Paulo, localizado à latitude de $22^{\circ} 42^{\prime} \mathrm{S}$, longitude $47^{\circ} 18^{\prime} \mathrm{W}$ e altitude de $550 \mathrm{~m}$, utilizando-se quatro bovinos mestiços, machos castrados, com cânulas no rúmen e com peso médio de 814 kg durante todo o experimento. Os animais foram mantidos em baias cobertas e individuais com cochos e bebedouros que permitiram a avaliação do consumo de alimentos.

O experimento foi desenvolvido em delineamento em quadrado latino $4 \times 4$ (Pimentel Gomes, 1985), segundo arranjo fatorial $2 \times 2$, composto de dois níveis de leucena (20 e 50\% MS) associados (L) ou não (S) à levedura na dieta:

- $20 \mathrm{~S}=80 \%$ de feno de gramínea $+20 \%$ de feno de leucena, sem levedura;

- $50 \mathrm{~S}=50 \%$ de feno de gramínea $+50 \%$ de feno de leucena, sem levedura;

- $20 \mathrm{~L}=80 \%$ feno de gramínea $+20 \%$ de feno de leucena + 10 g de levedura;

- $50 \mathrm{~L}=50 \%$ feno de gramínea $+50 \%$ de feno de leucena +10 g de levedura.
A alimentação foi fornecida duas vezes ao dia e $10 \mathrm{~g}$ de levedura (cultivo microbiano de Saccharomyces cerevisiae - estirpe 1026, cedida pela Empresa Alltech) foram colocados diretamente no rúmen de cada animal antes da primeira alimentação. Os animais tiveram livre acesso a uma mistura de sal mineral.

Cada período do quadrado latino teve duração de 21 dias, mantendo-se intervalo de sete dias entre cada período com o objetivo de diminuir os efeitos remanescentes da dieta anterior. Nesse período de descanso, os animais foram mantidos juntos, em piquete, e receberam uma dieta de mantença composta de feno de gramínea.

A biomassa da leguminosa Leucaena leucocephala (Lam.) de Wit. para produção do feno foi obtida em quatro diferentes épocas de corte: agosto de 2004, novembro de 2004, fevereiro de 2005 e abril de 2005 . O material foi colhido manualmente retirando-se as porções finais dos galhos com aproximadamente $1 \mathrm{~cm}$ de diâmetro. Em seguida, utilizou-se uma picadeira estacionária (J.F H11.F4 - corte 8) para processamento do material em partículas de aproximadamente $3 \mathrm{~cm}$. O material foi espalhado ao sol em piso de concreto e atingiu o ponto de feno em um dia, quando foi armazenado em galpão fechado.

O feno da gramínea Cynodon dactylon cultivar coast-cross foi produzido em janeiro de 2005 com 35 dias de crescimento vegetativo, em área adubada.

Amostras dos fenos de leucena e de coast-cross foram colhidas semanalmente e mantidas em temperatura de $-20^{\circ} \mathrm{C}$, para posterior análise química (Tabela 1). As análises de FDN e FDA das amostras foram realizadas no Laboratório de Bromatologia do Instituto de Zootecnia de Nova Odessa, São Paulo, segundo Goering \& Van Soest (1970), e as de matéria seca e proteína bruta, conforme metodologia descrita em AOAC (1995).

As análises de fenóis totais, taninos totais e taninos condensados foram realizadas pelo laboratório de Nutrição Animal do CENA/USP, em Piracicaba, São Paulo, com base nos resultados obtidos por Porter et al. (1986), Makkar et al. (1988), Makkar et al. (1993).

No $20^{\circ}$ dia de cada período, amostras do fluido ruminal foram coletadas para determinações de ácidos graxos voláteis e amônia com amostragens realizadas antes da alimentação matinal e 2, 4 e 8 horas depois. O fluido ruminal foi centrifugado imediatamente após a coleta e preservado com adição de 0,2 mL de ácido fórmico/mL de líquido ruminal para determinação de AGV em cromatografia gasosa, segundo Erwin et al. (1961).

A determinação da concentração de amônia (NH3) no líquido ruminal foi realizada segundo procedimentos 
Tabela 1 - Composição dos fenos e das dietas com $20 \%$ ou $50 \%$ de feno de leucena

\begin{tabular}{|c|c|c|c|c|c|}
\hline Constituinte & Feno de leucena & Feno de coastcross & $\% \mathrm{MS}$ & Dieta nível 20 & Dieta nível 50 \\
\hline Matéria seca & 92,68 & 92,97 & & 92,50 & 92,80 \\
\hline Extrato etéreo & 1,22 & 1,64 & & 1,56 & 1,43 \\
\hline Matéria mineral & 5,82 & 7,15 & & 6,88 & 6,49 \\
\hline Fibra em detergente ácido & 41,75 & 36,32 & & 37,41 & 39,04 \\
\hline N-FDN \% do nitrogênio total & 24,02 & 29,51 & & 28,41 & 26,77 \\
\hline Celulose & 26,14 & 30,90 & & 29,95 & 28,52 \\
\hline Lignina & 9,73 & 3,62 & & 4,84 & 6,68 \\
\hline Fenóis totais & 5,86 & 0,6 & & 1,65 & 3,23 \\
\hline Taninos totais & 4,72 & 0,3 & & 1,18 & 2,51 \\
\hline Taninos condensados & 2,63 & 0,01 & & 0,53 & 1,32 \\
\hline
\end{tabular}

descritos por Fenner (1965). O pH foi mensurado imediatamente após a coleta de aproximadamente $100 \mathrm{~mL}$ de fluido ruminal, nos mesmos tempos de amostragens de AGV e amônia. Para determinação da emissão de gás metano no rúmen, os animais foram adaptados ao aparato de amostragem (canga), durante 14 dias antes do início dos períodos experimentais, e permaneceram com as cangas durante todos os períodos. Este critério foi adotado para diminuir o estresse dos animais na colocação da canga. As coletas dos gases ruminais foram realizadas durante seis dias consecutivos, a intervalos de 24 horas, iniciando-se no $12^{0}$ dia experimental. A metodologia empregada na mensuração de metano foi aplicada com a técnica do traçador interno hexafluoreto de enxofre $\left(\mathrm{SF}_{6}\right)$, descrita por Johnson \& Johnson (1995) e adaptada por Primavesi et al. (2004). As concentrações de metano e hexafluoreto de enxofre foram determinadas por cromatografia gasosa. As análises foram realizadas nos laboratórios da EMBRAPA Meio Ambiente em Jaguariúna/SP.

Os dados obtidos foram analisados estatisticamente utilizando-se o procedimento GLM do programa estatístico SAS (2002). A verificação das fontes de variação foi feita por meio da análise de variância. As variáveis pH, AGV e amônia foram analisadas estatisticamente, como parcelas subdivididas no tempo e analisadas pelo PROC MIXED, que define as variáveis fixas e aleatórias para execução da análise. Os efeitos de dieta, animal e período foram testados nas parcelas. A interação horário de coleta $\times$ dieta foi testada nas subparcelas. Foram considerados $5 \%(\mathrm{P}<0,05)$ como nível de significância para a probabilidade do teste $\mathrm{F}$ na análise de variância. Para as variáveis com respostas significativas, utilizou-se o comando LSMEANS para as parcelas e subparcelas.

\section{Resultados e Discussão}

Os dois volumosos fornecidos aos animais apresentaram boa qualidade nutricional, com teores médios de proteína bruta semelhantes, porém, a leucena apresentou menores teores de fibra em detergente neutro e concentrações mais elevadas de fenóis e taninos (Tabela 1).

Não houve diferenças na ingestão de MS entre as dietas (Tabela 2), que se manteve abaixo dos valores encontrados na literatura para animais recebendo dietas contendo até 50\% de leucena (Pereira, 1994; Lourenço \& Carriel, 1998). Vitti et al. (2005), ao adicionarem leucena à dieta, observaram aumento na ingestão de matéria seca. A adição de leveduras também não modificou o consumo, que foi próximo a $1 \%$ do PV, fato também observado por Cabrera et al. (2000). Entretanto, independentemente da dieta e da baixa ingestão de matéria seca, os animais ganharam peso e mantiveram boas condições corporais durante o experimento.

Não foi constatado efeito da interação entre tempo, níveis de leucena e levedura $(\mathrm{P}>0,05)$ quando a análise foi realizada em cada tempo e com cada ácido (Tabela 3). Neste trabalho, nos níveis de AGV totais foram observados efeitos da interação entre níveis de leucena e levedura nas dietas $(\mathrm{P}<0,05)$. Quando a interação foi desdobrada, houve efeito significativo $(\mathrm{P}<0,05)$, comprovando que as concentrações dos AGV não foram favorecidas pelo maior nível de leucena na dieta, todavia, a adição de levedura na dieta aumentou a concentração média deste pool de ácidos na dieta com menor nível de leucena $(20$ L).

Os valores médios obtidos para os AGV totais nas dietas contendo levedura, 80,59 mM (50L) e 92,64 mM(20L) estão acima da concentração média $(74,3 \mathrm{mM})$ observada 
Tabela 2 - Ingestão de matéria seca (IMS) em bovinos recebendo dietas com dois níveis de leucena (20 ou 50\% MS), com (L) ou sem (S) levedura

\begin{tabular}{|c|c|c|c|c|c|c|c|c|c|c|}
\hline IMS & \multicolumn{2}{|c|}{ Nível $(\mathrm{N})^{1}$} & \multicolumn{2}{|c|}{ Levedura $(\mathrm{L})^{1}$} & $\mathrm{EPM}^{2}$ & \multicolumn{4}{|c|}{ Interação $(\mathrm{N} \times \mathrm{L})^{1}$} & $\mathrm{EPM}^{2}$ \\
\hline $\mathrm{kg} / \mathrm{dia}$ & 7,4 & 7,4 & 7,3 & 7,5 & 0,27 & 7,3 & 7,3 & 7,4 & 7,6 & 0,39 \\
\hline $\mathrm{g} / \mathrm{kg} \quad \mathrm{PC}^{0,75}$ & 48,3 & 48,6 & 47,7 & 49,2 & 1,63 & 47,8 & 47,5 & 48,7 & 49,6 & 2,30 \\
\hline
\end{tabular}

${ }^{1}$ As diferenças foram não-significativas $(P>0,05)$ pelo teste $F$ para os efeitos de níveis $(N)$, levedura $(L)$ e da interação $N \times L .2$. EPM - erro-padrão da média. $\mathrm{PC}=$ peso corporal.

por Roa et al. (1997) em bovinos recebendo dieta a base de feno de alfafa e levedura e também obtidos por Manella et al. (2003) em animais mantidos em pastagem de Brachiaria suplementadas com leucena durante um ano, que variaram de 63 a $74 \mathrm{mM}$.

De acordo com Giger-Reverdin et al. (1996), a adição de levedura à dieta aumenta a quantidade dos AGV totais, tanto in vitro como in vivo - em virtude da produção de aminoácidos, nucleotídeos e vitaminas que estimulam o crescimento e a atividade bacteriana - e leveduras vivas são eficientes na produção desses co-fatores. McGinn et al. (2004) não encontraram diferenças na produção de AGVs totais quando adicionaram levedura em dieta à base de silagem com 36\% de FDN na MS.

As concentrações de ácido acético não diferiram $(\mathrm{P}>0,05)$ entre as dietas. Este ácido é sempre produzido em maior quantidade que os outros ácidos graxos voláteis do rúmen e suas concentrações não variaram muito com a espécie vegetal utilizada na dieta. Os níveis de leucena na dieta, embora seja uma leguminosa de alta qualidade e contenha o aminoácido tóxico mimosina, não afetaram a concentração de ácido acético no rúmen, provavelmente por tratar-se de uma dieta exclusivamente volumosa, o que impede qualquer influência da levedura sobre sua concentração.

Os teores de ácido propiônico sofreram efeitos significativos dos níveis de leucena na dieta $(\mathrm{P}<0,05)$, ocorrendo a interação de níveis de leucena e levedura $(\mathrm{P}<0,05)$. O menor valor médio obtido da porcentagem molar do ácido propiônico (17,56 mM) foi observado em animais consumindo baixo nível de leucena com adição de levedura. Com o aumento da leucena na dieta houve maior produção de ácido propiônico (19,14 mM), logo, o efeito da leucena em nível elevado foi potencializado pela adição de levedura.

Não houve diferenças significativas $(\mathrm{P}>0,05)$ nas concentrações médias de ácido butírico entre níveis de leucena e levedura; porém, foram detectados efeitos significativos $(\mathrm{P}<0,05)$ da interação entre níveis e levedura e as maiores concentrações de ácido butírico foram observadas com o fornecimento da dieta com $20 \%$ de leucena.
Segundo Pereira (1994), a produção de ácido propiônico tende a decrescer com o avanço da maturidade das planta e tem relação inversa com o ácido acético. Em dietas com elevada participação de leguminosas, embora não existam grandes diferenças nas concentrações de ácido acético, há menor concentração de ácido, enquanto pode ocorrer aumento da concentração média de ácido butírico. Neste experimento, observou-se maior proporção molar de ácido propiônico na dieta com os maiores níveis de leucena, contrariando as informações de Pereira (1994). Com relação ao ácido butírico, os valores observados estão relacionados à interação com a presença de levedura na dieta, evidenciando maior interação na dieta com $20 \%$ de leucena, que aprensentou as maiores proporções molares desse AGV.

As concentrações e as proporções entre os ácidos acético, propiônico, butírico dependem muito da natureza da dieta e de seu valor nutritivo. Neste trabalho, constatou-se heterogeneidade nas concentrações desses ácidos (acético, propiônico e butírico) em relação aos níveis de leucena. As diferenças não parecem ter uma correspondência com o valor nutritivo, mas sim com a proporção da leguminosa na dieta e com a adição da levedura, que influencia as concentrações dos ácidos propiônico e butírico e a produção total dos AGV. Ngwa et al. (2003), em experi-mentocom espécies leguminosas, observaram que a dieta contendo leucena aumentou a concentração dos isoácidos. Segundo os autores, a fermentação da matéria orgânica da leucena parece seguir uma via de fermentação um pouco diferente das outras leguminosas estudadas.

Manella et al. (2003) observaram aumento apenas na concentração média do ácido butírico em relação aos demais AGV em animais recebendo leucena na dieta. A adição de leveduras na alimentação de ruminantes, muitas vezes tem provocado efeitos na concentração dos AGV do rúmen. Pesquisas conduzidas com diferentes condições de dietas comprovaram aumento na concentração dos ácidos acético, propiônico e butírico (Giger-Reverdin et al., 1996; Roa et al., 1997; Garcia et al., 2000, Lila et al., 2004). Entretanto, outros autores não detectaram diferenças na produção dos AGV 
do rúmen (Olson et al., 1994; Mc Ginn et al., 2004; Knorr et al., 2004).

Houve efeitos significativos $(\mathrm{P}<0,05)$ nas relações de acético:propiônico para níveis de leucena. Os níveis mais altos níveis da leguminosa na dieta favoreceram esta relação. A adição de levedura parece ter favorecido o aumento na proporção molar do ácido propiônico quando altos níveis da leguminosa estavam presentes na dieta.

A relação ácido acético:propiônico (Ac:Pr) é um relevante ponto de destaque no estudo da metanogênese ruminal. Se esta relação chegar a 0,5 , a perda de energia pode ser nula, porém, se todos os carboidratos forem fermentados a ácido acético e não produzirem nenhum ácido propiônico, as perdas energéticas podem chegar a 33\%. A relação Ac: $\operatorname{Pr}$ pode variar entre 0,9 a 4,0, e, portanto, as perdas por metano podem variar amplamente (Johnson \& Johnson, 1995). As menores relações Ac:Pr foram observadas nos animais consumindo os mais altos níveis da leguminosa na dieta, o que confirma as afirmações de Carmona (2005), que defende a inclusão de leguminosas arbóreas e arbustivas aos sistemas produtivos de gado com o intuito de diminuir a emissão do gás metano e o impacto ambiental e produtivo.

Não foram observadas diferenças significativas $(\mathrm{P}>0,05)$ entre níveis de leucena na presença ou ausência de levedura na dieta. O efeito de tempo para as concentrações de amônia foi quadrático e altamente significativo $(\mathrm{P}<0,01)$, variabilidade comum em ruminantes alimentados nas condições deste estudo (Mehrez \& Ørskov 1977).
Segundo Van Soest (1994), o metabolismo da proteína dietética no rúmen é resultado da hidrólise de peptídeos a amimoácidos, que podem ser usados para síntese de proteína microbiana ou para formar pequenos peptídeos. Aminoácidos em excesso para os microrganismos são oxidados e deaminados a amônia e ácido carboxílico. A disponibilidade de carboidratos promove a utilização da amônia para síntese de aminoácidos e crescimento microbiano. O nível de amônia ruminal ótimo é em torno de $10 \mathrm{mg} / 100 \mathrm{~mL}$. Entretanto, esse valor médio sofre variação, uma vez que as bactérias são capazes de sintetizar proteína. Veloso et al. (2000) observaram valor médio de amônia de 26 mg/100mL no rúmen em três tempos de amostragem (3, 6 e 12 horas após alimentação). Quando utilizaram na dieta feno de gramíneas tropicais de boa qualidade, a concentração média observada variou de 18,71 a 21,28 mg/100 mL, dentro dos níveis recomendados para se obter o maior desaparecimento de matéria seca (Mehrez \& Ørskov, 1977). Manella et al. (2003), trabalhando com animais em regime de pasto recebendo leucena como suplementação protéica, obtiveram valores muito abaixo aos observados no presente trabalho (1,3 a 3,1 mg/100 mL).

Roa et al. (1997) observaram aumentos significativos nas concentrações médias de amônia, de 27,7 para 36,3 mg/ $100 \mathrm{~mL}$, quando adicionaram levedura a uma dieta contendo feno de alfafa. Franzolin et al. (2004) não detectaram diferenças significativas nos valores médios da concentração de amônia ruminal $(15,25 \mathrm{mg} / 100 \mathrm{~mL})$ com a adição de leveduras a uma dieta com $75 \%$ de feno de gramínea.

Tabela 3 - Ácidos graxos voláteis, $\mathrm{N}$-amoniacal $\left(\mathrm{N}-\mathrm{NH}_{3}\right)$ e $\mathrm{pH}$ do líquido ruminal de bovinos recebendo dieta com dois níveis de leucena ( $20 \%$ ou $50 \%$ MS), com (L) ou sem (S) levedura

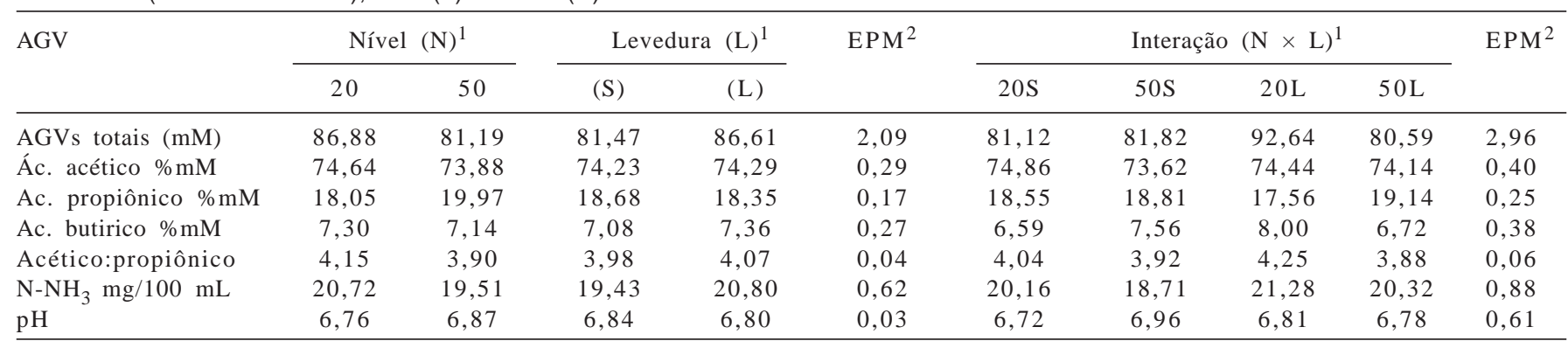

Probabilidade $^{3}$

\begin{tabular}{|c|c|c|c|c|c|c|c|}
\hline & \\
\hline Ácido acético & $\mathrm{ns}^{4}$ & $\mathrm{~ns}^{4}$ & $\mathrm{~ns}^{4}$ & - & - & - & - \\
\hline Ácido butirico & $\mathrm{ns}^{4}$ & $\mathrm{~ns}^{4}$ & 0,0270 & $\mathrm{~ns}^{4}$ & 0,0572 & 0,0421 & $\mathrm{~ns}^{4}$ \\
\hline Acético:propiônico & 0,0039 & $\mathrm{~ns}^{4}$ & $\mathrm{~ns}^{4}$ & - & - & - & - \\
\hline $\mathrm{N}-\mathrm{NH}_{3} 5$ & $\mathrm{~ns}^{4}$ & $\mathrm{~ns}^{4}$ & $\mathrm{~ns}^{4}$ & - & - & - & - \\
\hline
\end{tabular}

${ }^{1}$ Níveis de leucena $(N)$ com levedura $(L)$ e sem levedura $(L)$ e a interação desses fatores

2 EPM: erro-padrão da média.

3 Valores de $P$ para o efeito de níveis $(N)$, efeito de levedura $(L)$ e efeito da interação $(N \times L)$ e desdobramento das interações $N /(S), N /(L), L / N 20$ e $L / N 50$.

4 ns - não-significativo.

${ }^{5}$ Efeito de tempo quadrático $(P<0,0001)$. As interações $N \times T, L \times T$ e $N \times L \times T$ não foram significativas $(P>0,05)$. 
Os níveis da leguminosa na dieta não influenciaram as concentrações de amônia no líquido ruminal. Esta ocorrência pode ser explicada pelo fato de que, em ambas as dietas, os animais receberam o mesmo teor de proteína, uma vez que o feno de coast-cross utilizado apresentou teor de $\mathrm{PB}$ similar ao feno de leucena, com média de 17\% de PB.

Os valores médios do $\mathrm{pH}$ do fluido ruminal (Tabela 3) variaram entre 6,72 e 6,96, valores típicos de dietas volumosas. Houve efeito de níveis de leucena $(\mathrm{P}<0,05)$ e interação de níveis e levedura $(\mathrm{P}<0,05)$ sobre os valores de $\mathrm{pH}$, que foram maiores e mais estáveis na dieta 50S.

$\mathrm{O}$ pH é considerado fator importante quando se relaciona a produção de metano ao metabolismo ruminal. Segundo Van Kessel \& Russell (1996) e Lana et al. (2000), bovinos recebendo dietas exclusivas de forragens apresentam $\mathrm{pH}$ ruminal relativamente com pequena variação $(6,6$ a 6,9), mas, quando recebem concentrado na dieta, o pH diminui para valores abaixo de 5,4. Bactérias no rúmen em animais com dietas exclusivas de forragens convertem $\mathrm{CO}_{2}$ e $\mathrm{H}_{2}$ em metano, enquanto, com dietas à base de concentrados ou de forrageiras de muito boa qualidade, a produção de metano diminui drasticamente quando o pH é menor que 6,0. Neste trabalho, as forragens fornecidas aos animais foram de excelente qualidade, entretanto, o pH ruminal não apresentou valores abaixo de 6,5 e a produção de metano foi relativamente baixa. Os valores obtidos, no entanto, foram semelhantes aos encontrados por outros pesquisadores com bovinos recebendo dietas ricas em volumosos (Pedreira et al., 2004; Primavesi et al., 2004).

Outro ponto a ser observado é que a adição de leveduras não modificou o pH ruminal. A levedura tem sido destacada pelo fato de manter o $\mathrm{pH}$ mais estável no rúmen por estimular o crescimento de bactérias celulolíticas em dietas ricas em amido (Merten \& Ely, 1982; Ørskov \& Ryle, 1990), entretanto, em dietas exclusivamente volumosas, seus efeitos são contraditórios. Neste trabalho, o pH ruminal foi mais estável na ausência da levedura, o que confirma resultados obtidos por outros autores que desenvolveram experimentos com uso de levedura em dietas para ruminantes (Garcia et al., 2000; Mc Ginn et al., 2004).

Os valores médios da produção de metano ruminal (Tabela 4) apresentaram diferenças $(\mathrm{P}<0,05)$ quando expressos em g/hora, g/dia e kg/ano para níveis de leucena e houve efeito da interação com levedura na dieta. Os valores médios da emissão de gás metano foram menores (127 a 156 g/animal/dia) que os relatados por Johnson \& Johnson (1995) em estimativas para gado de corte (164 a $194 \mathrm{~g} /$ animal/dia) e gado de leite (298 a 345 g/animal/dia). Pedreira et al. (2004), estudando a emissão do gás metano em bovinos machos mestiços consumindo dieta exclusiva de silagem de sorgo e com 30 e $60 \%$ de concentrado, obtiveram valores próximos aos observados neste experimento, de 125, 149 e 140 g/dia, respectivamente. Primavesi et al. (2004a), avaliando a produção de metano no rúmen de gado leiteiro em pastagens de Pannicum maximum, observaram valores da emissão do gás de 198 a 222 g/dia em novilhas, 403 g/dia em vacas em lactação e 278 g/dia em vacas não-lactantes. Os autores enfatizaram que os dados obtidos com animais em lactação estão muito acima dos valores médios observados na América Norte. A técnica empregada neste estudo foi a mesma utilizada por esses autores para captura e determinação de metano.

Na produção do metano ruminal, quando expresso em grama/kg de MS ingerida, houve efeito da interação de níveis de leucena e levedura $(\mathrm{P}<0,05)$. Na ausência de levedura, o aumento do nível de leucena de 20 para 50\% promoveu aumento de $2,0 \%$ na produção de metano no rúmen, enquanto, com a adição de levedura, houve redução de 17,2\% de metano no rúmen. Neste último caso, houve coerência com o padrão de fermentação no rúmen, em virtude do aumento de 9,0\% obtido na produção de ácido propiônico (Tabela 3). Com dietas contendo baixo nível de leucena, houve aumento de $8,5 \%$ na produção de gás metano quando a levedura foi incluída na dieta e redução de 5,3\% da produção de ácido propiônico, enquanto, em dietas com alto nível de leucena, houve redução de $12,3 \%$ do metano e aumento de 1,8\% na concentração de ácido propiônico produzido pelos microrganismos no rúmen. Dessa forma observou-se relevante efeito associativo do alto nível de leucena na dieta com a presença de levedura na redução da produção de gás metano e na melhora do padrão de fermentação no rúmen.

Segundo Carmona (2005), a opção para a redução das emissões de metano consiste na substituição de tecnologias convencionais por alternativas que associem produção com mínimos efeitos ambientais. A implementação de práticas de manejo em pastos visando melhoraria de qualidade, em geral, tem efeitos significativos na redução da emissão do gás metano. De acordo com o autor, é evidente o efeito positivo das leguminosas de espécies arbóreas e arbustivas nas dietas e nos sistemas silvipastoris para animais em pastejo de gramíneas tropicais de baixa qualidade. Além do ganho nutricional, outros aspectos que resultam em melhoras edáficas e bem-estar animal ficam bastante evidentes nestes sistemas.

Puchala et al. (2005) sugeriram que forragens contendo baixos ou moderados teores de taninos condensados ( $2 \%$ a $17 \%$ ) diminuem a emissão de metano em ruminantes. Os 
Tabela 4 - Emissão de gás metano (CH4) em bovinos recebendo dieta com dois níveis de leucena (20\% ou 50\% MS), com (L) ou sem (S) levedura

\begin{tabular}{|c|c|c|c|c|c|c|c|c|c|c|}
\hline \multirow[t]{2}{*}{ Metano } & \multicolumn{2}{|c|}{ Nível $(\mathrm{N})^{1}$} & \multicolumn{2}{|c|}{ Levedura (L) ${ }^{1}$} & \multirow[t]{2}{*}{$\mathrm{EPM}^{2}$} & \multicolumn{4}{|c|}{ Interação $(\mathrm{N} \times \mathrm{L})^{1}$} & \multirow[t]{2}{*}{$\mathrm{EPM}^{2}$} \\
\hline & 20 & 50 & (S) & (L) & & $20 \mathrm{~S}$ & $50 \mathrm{~S}$ & $20 \mathrm{~L}$ & $50 \mathrm{~L}$ & \\
\hline g/hora & 6,15 & 5,37 & 5,62 & 5,90 & 0,33 & 5,79 & 5,44 & 6,51 & 5,30 & 0,47 \\
\hline g/dia & 147,5 & 128,9 & 134,7 & 141,7 & 8,01 & 138,9 & 130,5 & 156,2 & 127,3 & 11,4 \\
\hline kg/ano & 53,86 & 47,04 & 49,17 & 51,72 & 2,94 & 50,69 & 47,65 & 57,03 & 46,42 & 4,16 \\
\hline \multirow[t]{3}{*}{$\mathrm{g} / \mathrm{kg}$ de $\mathrm{MSI}^{4}$} & 19,69 & 18,08 & 19,07 & 18,69 & 1,11 & 18,89 & 19,26 & 20,49 & 16,90 & 1,57 \\
\hline & \multicolumn{10}{|c|}{ Probabilidade $^{2}$} \\
\hline & \multicolumn{2}{|c|}{ Nível (N) } & Levedura (L) & $\mathrm{N} \times \mathrm{L}$ & $\mathrm{N} / \mathrm{S}$ & \multicolumn{2}{|r|}{$\mathrm{N} / \mathrm{L}$} & $\mathrm{L} / \mathrm{N} 20$ & \multicolumn{2}{|c|}{$\mathrm{L} / \mathrm{N} 50$} \\
\hline g/hora & \multicolumn{2}{|c|}{0,0470} & $\mathrm{~ns}^{3}$ & 0,0500 & $\mathrm{~ns}^{3}$ & \multicolumn{2}{|r|}{0,0106} & $\mathrm{~ns}^{3}$ & \multicolumn{2}{|c|}{$\mathrm{ns}^{3}$} \\
\hline g/dia & \multicolumn{2}{|c|}{0,0470} & $\mathrm{~ns}^{3}$ & 0,0500 & $\mathrm{~ns}^{3}$ & \multicolumn{2}{|r|}{0,0106} & $\mathrm{~ns}^{3}$ & \multicolumn{2}{|c|}{$\mathrm{ns}^{3}$} \\
\hline kg/ano & \multicolumn{2}{|c|}{0,0470} & $\mathrm{~ns}^{3}$ & 0,0500 & $\mathrm{~ns}^{3}$ & \multicolumn{2}{|r|}{0,0106} & $\mathrm{~ns}^{3}$ & \multicolumn{2}{|c|}{$\mathrm{ns}^{3}$} \\
\hline $\mathrm{g} / \mathrm{kg}$ de MSI & \multicolumn{2}{|c|}{$n s^{3}$} & $\mathrm{~ns}^{3}$ & 0,0500 & $\mathrm{~ns}^{3}$ & \multicolumn{2}{|r|}{0,0031} & 0,0438 & \multicolumn{2}{|c|}{$\mathrm{ns}^{3}$} \\
\hline
\end{tabular}

1 EPM - erro-padrão da média.

2 Valores de $P$ para o efeito de níveis $(N)$, efeito de levedura $(L)$ e efeito da interação $(N \times L)$, e desdobramento das interações N/S, N/L, L/N20 e L/N50.

3 ns - não-significativo.

$4 \mathrm{MSI}$ - matéria seca ingerida.

autores observaram diminuição na produção de metano no rúmen de 50\% (6,9 vs 16,2 g/kg de MS ingerida) quando forneceram aos animais uma leguminosa com $17 \%$ de tanino condensado em comparação a uma gramínea contendo apenas 0,5\% deste composto. Dessa forma, neste experimento, a dieta com nível mais elevado de leucena continha $2,51 \%$ de tanino totais, enquanto a dieta com $20 \%$ de leucena continha $1,18 \%$, o que representa aumento de $113 \%$. Isso pode ter sido uma causa do efeito associativo de leucena com a levedura na redução da produção de metano conforme sugerido por Purhala et al. (2005).

Outras pesquisas são necessárias para o esclarecimento desse relevante efeito associativo de dietas com leucena e levedura na redução da emissão de metano e na melhoria da eficiência energética pelos ruminantes.

\section{Conclusões}

Dietas com 50\% de leucena e 50\% de gramínea promovem melhor padrão de fermentação no rúmen de bovinos. A produção de ácido propiônico aumenta e a emissão de metano reduz em $12,3 \%$ com o fornecimento dessas dietas sem leveduras. Contendo $20 \%$ de leucena e $10 \%$ de levedura, essas dietas reduzem em $17,2 \%$ a produção de ácido propiônico e a emissão de metano, demonstrando relevante efeito associativo do alto nível de leucena e do uso de levedura na redução da emissão de metano e melhoria da eficiência energética pelos ruminantes.

\section{Literatura Citada}

ASSOCIATION OF OFFICIAL ANALYTICAL CHEMISTS AOAC. Official methods of analysis. Washington D.C.: 1995. p.1051.
ARAKAKI, L.C.; STAHRINGIER, R.C.; GARRET, J.E. et al. The effects of feeding monensin and yeast culture, alone or in combination, on the concentration and generic composition of rumen protozoa in steers fed on low-quality pasture supplemented with increasing levels of concentrate. Animal Feed Science and Technology, v.84, p.121-127, 2000.

CABRERA, E.J.I.; MENDONZA, M.G.D.; ARANDA, I.E. et al. Saccharoyces cerevisae and nitrogenous supplementation in growing steers grazing tropical pastures. Animal Feed Science Technology, v.83, p.49-55, 2000.

CARMONA, J.C. El gás metano en la productión ganadera y alternativas para medir sus emisiones y aminorar su impacto a nivel ambiental y produtivo. Revista Colombiana de Ciências Pecuaria, v.18, p.49-63, 2005.

DEHORITY, B.A. Laboratory manual for classification and morphology of rumen ciliate protozoa. Florida: CRC Press, 1993. 96p.

ERWIN, E.S.; MARCO, G.J.; EMERY, E.M. Volatile fatty acid analyses of blood and rumen fluid by gas chromatografhy. Animal Feed Science Technology, v.44, p.1768-1771, 1961.

FENNER, H. Method for determining total volatile bases in rumen fluid by steam distillation. Journal Dairy of Science, p.249251, 1965.

FRANZOLIN, R.; COSTA, F.A.A.; FERNANDES, L.B. et al. Avaliação do uso de aditivos em dietas de bovinos zebuínos. In. REUNIÃO ANUAL DA SOCIEDADE BRASILEIRA DE ZooteCniA, 41., 2004, Campo Grande. Anais... Campo Grande: Sociedade Brasileira de Zootecnia, 2004. (CDROM).

GALINDO, J.; MARRERO, Y.; GONZALES, N. et al. Effect of foliage of two tropical trees (Brosimum allicastrum and Leucaena leucocephla) on the ruminal microbial population in in vitro conditions. Cuban Journal of Agriculture Science, v.37, p.389-395, 2003.

GARCIA, C.C.G.; MENDONZA, M.G.D; GONZÁLES, M.S. et al. Effect of a yeast culture (Saccharomyces cerevisae) and monensin on ruminal fermentation and digestion in sheep. Animal Feed Science Technology, v.83, p.165-170, 2000.

GIGER-REVERDIN, S.; BEZAULT, N.; SAUVANT, D. et al. Effects of a probiotic yeast in lactating ruminants: interaction with dietary nitrogen level. Animal Feed Science and Technology, v.63, p.149-162, 1996.

GOERING, H.K.; Van SOEST, P.J. Forage fiber analysis. Washington, D.C.: 1970. 20p. (Agriculture Handbook, 379).

JOHNSON, K.A.; JOHNSON, D.E. Methane emissions from cattle. Journal of Animal Science, v.73, p.2483-2492, 1995. 
KNORR, M. PATINO, H.O; MEDEIROS, F.S. et al. Efeito de diferentes níveis de nitrogênio não protéico em sais proteinados no $\mathrm{pH}$ e na concentração de amônia ruminal de bovinos alimentados com feno de baixa qualidade. In: REUNIÃO ANUAL DA SOCIEDADE BRASILEIRA DE ZOOTECNIA, 41., 2004, Campo Grande. Anais... Campo Grande: Sociedade Brasileira de Zootecnia, 2004. (CD-ROM).

LANA, P.R.; RUSSELL, J.B.; Van AMBURGH, M.E. The role o $\mathrm{pH}$ in regulating ruminal methane and ammonia production. Journal of Animal Science, v.76, p.2190-2196, 1998.

LILA, Z.A.; MOHAMMED, N.; YASUI, T. et al. Effects of a twin strain of Saccharomyces cerevisae live cells on mixed ruminal microorganism ferementation in vitro. Journal of Animal Science, v.82, p.1847-1854, 2004.

LOURENÇO, A.J.; CARRIEL, J.M. Desempenho de bovinos em pastagens de Brachiaria brizantha associados a Leucaena Leucocephala. Boletim da Indústria Animal, v.55, n.1, p.4550, 1998.

MAKKAR, H.P.S; BLUMMEL, M.; BECKER, K. Gravimetric determination of tannins and their correlation with chemical and protein precipitation methods. Journal Science of Food Agriculture, v.61, p.161-165, 1993.

MAKKAR, H.P.S; DAWRA, R.K.; SINGH, B. Determination of both tannin and protein in a tannin-protein complex. Journal Agricultural Food Chemists, v.36, p.523-525, 1988.

MANELLA, Q.M.; LOURENÇO, J.A.; LEME, P.R. Recria de bovinos nelore em pastos de Brachiaria brizantha com suplementação protéica ou com acesso a banco de proteína de Leucaena lecocephala. Características de fermentação ruminal. Revista Brasileira de Zootecnia, v.32, n.4, p.1002-1012, 2003.

McGINN, S.N.; BEAUCHEMIN, K.A.; COATES, T. et al. Methane emissions from beef catle: effects of monesin, sunflower oil, enzymes, yeast, and fumaric acid. Journal of Animal Science, v.82, p.3346-3356, 2004.

MEHREZ, A.Z.; ORSKOV, E.R. A study of the artificial fibre bag technique for determining the digestibility of feeds in the rumen. Journal of Agriculture Science, v.88, p.645-650, 1977.

MERTEN, D.R.; ELY, L.O. Relation ship of rate and extent of digestión to forage utilization, a dynamic model evaluation. Journal of Animal Science, v.54, p.895-905, 1982.

NGWA, A.T.; NSAHLAI, I.V.; IJI, P.A. Effect of feeding legume pods or alfalfa in combinationwith poor quality grass straw on microbial enzyme activity and production of VFA in the rumen os South African Merino sheep. Small Ruminants Research, v.48, p.83-94, 2003.

OLSON, K.C.; CATON, J.S.; KIRBY, D.R. et al. Influence of yeast culture supplementation and advancing season on steers grazing mixed-grass prairie in the Northern Great Plain: II ruminal fermentation, site of digestion, and microbial efficiency. Journal of Animal Science, v.72, p.2158-2170, 1994.

ØRSKOV, E.R.; RYLE, M. Energy nutrition in ruminants. London: Elsevier, 1990. 149p.

ORTOLAN, J.H.; NOGUEIRA FILHO, J.C.; CASTRO, A.L. et al. Efeito da adição de aditivos sobre a fauna ruminal em novilhos nelore alimentados com dieta de terminação. BIOTAM Nueva Serie, Edición Especial, p.92-94, 2005.

PEDREIRA, M.S.; BERCHIELLI, T.T.; OLIVEIRA, S.G. et al. Produção de metano e concentração de ácidos graxos voláteis ruminal em bovinos alimentados com diferentes relações de volumoso:concentrado. In: REUNIÃO ANUAL DA SOCIEDADE BRASILEIRA DE ZOOTECNIA, 41., 2004, Campo Grande. Anais... Campo Grande: Sociedade Brasileira de Zootecnia, 2004. (CD-ROM).

PEREIRA, A.M.F. Avaliação da toxicidade por dihidroxipiridina através do consumo de Leucaena leucocephala (Lam.) de Wit. em três raças de bovídeos. Lisboa: Universidade Técnica de Lisboa, 1994. 117p. Dissertação (Mestrado em Medicina Veterinária e Zootecnia Tropicais) Universidade Técnica de Lisboa, 1994.

PIMENTEL GOMES, F. Curso de estatística experimental. Piracicaba: Escola Superior de Agricultura Luiz de Queiroz, 1985. 466p.

PORTER, L.J.; HRSTICH, L.N.; CHAN, B.G. The conversion of procyanidins and prodelphinidins to cyaniding and delphinidin. Phytochemistry, v.25, p.223-230, 1986.

PRIMAVESI, O.; FRIGHETO, R.T.S.; PEDREIRA, M.S. et al. Técnica do gás traçador SF6 para medição de campo do metano ruminal em bovinos: adaptações para o Brasil. São Carlos: Embrapa Pecuária Sudeste, 2004. 74p. (Documento, 39)

PRIMAVESI, O.; TRIGHETTO, R.T.S.; PEDEDREIRA, M.S. et al. Metano entérico de bovinos leiteiros em condições tropicais brasileiras. Pesquisa Agropecuária Brasileira, v. 39, p. 277 283, 2004a.

PUCHALA, R.; MIN, R.B.; GOETSCH, A.L. et al. The effect of a condensed tannin-containing forage on methane emission by goats. Journal of Animal Science, v.83, p.182-186, 2005.

ROA, M.L.; BARCENA-GAMA, J.R.; GONZÁLES, S.M. et al. Effect of fiber source and a yest culture (Saccharomyces cerevisae ${ }^{1026}$ ) on digestion and the environment in the rumen of cattle. Animal Feed Science and Technology, v.64, p.327-336, 1997.

STATISTICAL ANALYSIS SYSTEM - SAS. SAS user's guide statistics. 5.ed. Cary: SAS Institute, 2002. (CD-ROM).

VALARINI, M.J.; POSSENTI, R.A. Stem-nodulating Sesbania as a potential feed supplement for ruminants. Tropical Science, v.4, p.64-69, 2004.

Van KESSEL, J.A.S.; RUSSEL, J.B. The effect of $\mathrm{pH}$ on ruminal methanogenesis. FEMS Microbiology Ecology, v.20, p.205210, 1996.

Van SOEST, P.J. Nutritional ecology of the ruminant. 2.ed. London: Comstock Publishing Associates, 1994. 476p.

VELOSO, C.M.; RODRIGUEZ, N.M.; SAMPAIO, I.M.B. et al. pH e amônia ruminais, relação folhas:hastes e degradabilidade ruminal da fibra de forrageiras tropicais. Revista Brasileira de Zootecnia, v.29, p.871-879, 2000.

VITTI, D.M.S.S.; ABDALLA, A.L.; BUENO, I.C.S. et al. Do all tannins have similar nutritional effects? A comparison of three Brazilian fodder legumes. Animal Feed Science and Technology, v.119, p.345-361, 2005. 